\title{
EFETIVAÇÃO DO COMPLIANCE COMO UMA EFETIVA CULTURA EMPRESARIAL NO BRASIL
}

\section{EFFECTIVENESS OF COMPLIANCE AS AN EFFECTIVE BUSINESS CULTURE IN BRAZIL}

\section{HORÁCIO MONTESCHIO}

Pós doutorando pela Universidade de Coimbra e pelo UNICURITIBA. Doutor em Direito pela FADISP. Mestre em Direitos da Personalidade - UNICESUMAR. Professor de Direito Administrativo e Processo Administrativo do UNICURITIBA. Professor do UNICESUMAR - Curitiba. ex-Secretário de Estado da Indústria e Comércio e Assuntos do Mercosul do Estado do Paraná, ex-Secretário Municipal para Assuntos Metropolitanos de Curitiba.

\section{VALÉRIA JULIANA TORTATO MONTESCHIO}

Graduada em Direito pela Universidade Estadual de Maringá. Graduada em Pedagogia, Mestre em Políticas Públicas da Educação, especialista em Gestão Educacional, professora na Faculdade FAEL e no UNIPOSITIVO. Autora da obra Direito da Criança e do Adolescente, advogada.

\section{RESUMO}

As boas práticas dentro do cenário das empresas brasileiras não pode ser uma mera imposição da lei, mas sim uma prática efetivada dentro de uma imposição cultural. É inegável o fato de que dentro das práticas empresariais no Brasil, diante da concorrência predatória em alguns segmentos, as quais acabam por impor, isso mesmo impor, àquele que pretende manter sua estrutura empresarial em pleno 


\section{Personalidade Acadêmica Homenageada:}

Augustus B. Cochran III (Agnes Scott College)

funcionamento acabar cedendo a posturas nada recomentadas, quando não violadoras da legislação vigente. Não se trata de impor restrições cada vez maiores e presentes na legislação pátria, tendo em vista que a sua efetividade, em muitas vezes, não vem a ser atingida. Cabe ressaltar que os órgãos de controle estatal, leia-se, Tribunais de Contas, Ministério Público e o próprio Poder Legislativo conseguem identificar e reprimir uma pequena parcela das práticas violadoras da boa conduta empresarial. A edição da Lei no 12.846/13 denominada de "lei anticorrupção" possui seus méritos, assim como as previsões contidas no Código Penal brasileiro, na Lei no 4.717/65 Lei da Ação Popular, Decreto-Lei no 201/65 que dispõe sobre a responsabilidade dos Prefeitos e Vereadores, Lei ำ 8.429/92 que trata sobre as prática de Improbidade Administrativa, Lei oㅜ 13.303, de 30 de junho de 2016, a qual dispõe sobre o estatuto jurídico da empresa pública, da sociedade de economia mista e de suas subsidiárias, no âmbito da União, dos Estados, do Distrito Federal e dos Municípios, não vem obtendo o êxito pretendido pelos seus idealizadores. Diante da ausência de efetividade dos diplomas legais citados e outros que poderiam sê-lo, somente resta a via social, pelo próprio aprimoramento cultural brasileiro, pelas vias alternativas, como por exemplo, das ouvidorias eficientes e engajadas, pela implantação de um programa de compliance atuante, para alterar o quadro atual de não atuação de forma ética e moral no interior da empresas. Somente pela via legislativa e pelos órgãos de controle não se está atingindo os fins esperados de reprimir e atenuar práticas ilegais e nocivas às empresas e a sociedade como um todo.

O método utilizado é o dedutivo. Problematização: Somente a legislação e os órgãos de controle não estão sendo suficientes para cumprir o papel de reprimir ou mitigar as práticas de corrupção no Brasil. Em termos legislativos o arcabouço legal brasileiro é de uma riqueza impressionante, que conta com legislação dos mais variados matizes, as quais buscam proteger os bens jurídicos mais variados. Cabe ressaltar mesmo diante de tão vasto campo legislativo não está se mostrando apto atender efetivamente seu desiderato. Pretende-se com o presente iniciar um debate no sentido de prestigiar, cada vez mais, as áreas de compliance, ou mesmo das 
Personalidade Acadêmica Homenageada:

Augustus B. Cochran III (Agnes Scott College)

ouvidorias das empresas, para que as mesmas venham a atuar na de práticas éticas, na defesa da empresa e da sociedade brasileira.

PALAVRAS-CHAVE: efetivação do Compliance; Função social da empresa; ineficácia legislativa.

\section{REFERÊNCIAS}

MARTINS, José Alberto Monteiro; KNOERR, Fernando Gustavo. The police power and compliance in a legal state and their influence on the anti-corruption law (law 12,846 dated august 1, 2013). Revista Jurídica - UNICURITIBA. Vol. 2 o 43, 2016, p. 351-387.

FERREIRA, Daniel; BERTONCINI, Mateus Eduardo Siqueira Nunes. A importância do controle cidadão nos programas de integridade (compliance) das empresas estatais com vistas ao desenvolvimento nacional. In: Revista Jurídica UNICURITIBA. Vol. 4 ํㅜ 45, 2016, p. 115-134.

LEDESMA, Thomás Henrique Welter; RODRIGUES, Maria Lúcia de Barros. Implementação do compliance na fundação nacional do índio - FUNAl. Revista Jurídica - UNICURITIBA. Vol. 2 no 43, 2016, p. 114-141. 